\title{
Uşak illinden Seçilmiş Ceviz Genotiplerinde Meyvelerin Mineral Madde İçerikleri
}

\author{
Ercan YILDIZ ${ }^{* 1}$, Ahmet SÜMBÜL ${ }^{2}$ \\ ${ }^{1}$ Erciyes Üniversitesi, Seyrani Ziraat Fakültesi, Bahçe Bitkileri Bölümü, Kayseri \\ ${ }^{2}$ Sivas Cumhuriyet Üniversitesi, Suşehri Timur Karabal MYO, Bitkisel ve Hayvansal Üretim Bölümü, Sivas
}

Öz: Ülkemizin değişik bölgelerinde yetiştirilen ceviz genotiplerinin mineral madde içeriklerinin tespiti konusunda çeşitli çalışmalar bulunmaktadır. Bu çalışma, tohumdan yetişmiş zengin ceviz gen kaynaklarına sahip Uşak ilinden seçilen 21 adet ümitvar ceviz genotiplerinde meyvelerin mineral madde içeriklerini belirlemek amacıyla yürütülmüştür. Çalışmada, seçilen genotiplerde iç ceviz meyvelerinin azot içeriklerinin \%2.10 ile 3.40 arasında değiştiği saptanmıştır. Genotiplerde diğer makro elementlerden ( $\mathrm{mg} / 100 \mathrm{~g}$ ) fosfor 210.93-411.15, potasyum 308.61 ve 480.82 , kalsiyum 149.63 ile 379.61 ve magnezyum 132.39 ile 224.81 arasında bulunmuştur. Genotiplerde meyvelerin demir (2.22-3.95 mg/100 g), çinko (1.62-3.26 mg/100 g), mangan (1.70-4.45 mg/100 g) ve bakır içerikleri $(0.63-2.55 \mathrm{mg} / 100 \mathrm{~g})$ farklııklar göstermiştir. Çalışma verileri topluca değerlendirildiğinde, Uşak ilinin değerli ceviz genotipleri barındırdığı ve bu genotipler içerisinde yüksek besin değeri içeren genotipler bulunduğu görülmüştür.

Anahtar Kelimeler: Uşak, genotipler, iç ceviz meyvesi, mineral madde içerikleri

Determination of Mineral Content in Kernel of Walnut Genotypes Selected from Uşak/Turkey

\begin{abstract}
There are several studies on the determination of mineral content of walnut genotypes grown in different regions of Turkey. This study was conducted to determine the mineral content in kernel of 21 promising walnuts (Juglans regia L.) genotypes selected from Uşak (Turkey), where walnut trees are grown widely from seeds. In the walnut kernel of selected genotypes, nitrogen content ranged from 2.10 to $3.40 \%$. Selections had a range of 210.93-411.15 mg/100 g for phosphorus content, 308.61-480.82 mg/100 g for potassium content, $149.63-$ $379.61 \mathrm{mg} / 100 \mathrm{~g}$ for calcium content and $132.39-224.81 \mathrm{mg} / 100 \mathrm{~g}$ for magnesium content. The contents of iron (2.22-3.95 mg/100 g), zinc $(1.62-3.26 \mathrm{mg} / 100 \mathrm{~g})$, manganese $(1.70-4.45 \mathrm{mg} / 100 \mathrm{~g})$ and copper $(0.63-2.55 \mathrm{mg} / 100 \mathrm{~g})$ were determined as the quantity in the selected genotypes. According to results of study, it is observed that Uşak province has valuable walnut genotypes and nutritious walnuts are found among these genotypes.
\end{abstract}

Keywords: Uşak, genotypes, walnut kernel, mineral contents

\section{GíRiş}

İnsanların Dünya'da geniş bir yayılım alanı gösteren ve ticari bakımdan diğer meyve türlerine göre daha fazla öneme sahip olan ceviz (Juglans regia L.), tüm dünyada sevilerek tüketilen meyve türüdür. Dünya üzerinde 18 türü olan cevizin ekonomik bakımdan en önemlisi Anadolu cevizi veya İran cevizi olarak bilinen Juglans regia L. türü olup, bu türün anavatanlarından biri de ülkemizdir (Şen, 1986).

Ağacı, meyvesi, yaprağı ve kerestesi ile hem çeşitli sektörlere ham madde sağlayan hem de çeşitli şekillerde işlenerek gıda sektöründe kullanılmasıyla insan beslenmesinde önemli bir yere sahip olan ceviz, 2017 yılı verilerine göre, dünya bazında üretim miktarı 3.829.626 tondur. Dünya ceviz üretiminde 1.925 .403 tonluk üretimi ile Çin ilk sırada yer alırken, diğer önemli ceviz üreticisi ülkeler ABD (571.526 ton), İran (349.192 ton) ve Türkiye (210.000)'dir (Anonim, 2017). Ülkemiz ceviz türünde 9.875.068 adet meyve veren yaşta ağaç sayısına sahiptir (Anonim, 2018a). Ülkemiz dünya ceviz üretiminde 4.sırada yer almamıza rağmen, ceviz ticareti konusunda istenilen konumda değildir. Ülkemizde ceviz yetiştiriciliği son yıllara kadar tohumdan yetişmiş ağaçlarla gerçekleştirilirken, bugüne kadar verimlilik ve standart ürün elde etmede istenilen ekonomik getiri sağlanamamıştır. Ancak heterozigot yapıya sahip olan cevizin tohumdan yetiştirilmesi, yetiştiği bölgenin şartlarına uyum sağlamış farklı özelliklere sahip genetik varyasyon zenginliği oluşturmuştur. Ülkemiz sahip olduğu farklı coğrafik ve ekolojik özelliklerden dolayı, hemen her bölgede adaptasyon yeteneği yüksek olan ceviz varlığına rastlamak mümkündür. Son yılarda devlet eliyle yapılan tarımsal destekler sayesinde, tohumdan yetişmiş ağaçlar şeklindeki yetiştiricilik yerini yerli ve yabancı çeşitlerle kurulu kapama bahçelere bırakmaya başlamıştır.

Akdeniz diyetinin önemli bir parçası olan ceviz, dünyada ki birçok topluluk açısından önemli bir besin kaynağıdır (Tapia ve ark., 2013). Zengin besin içeriğine sahip olan ceviz meyvesi, yağ (\%50-80), protein (\%12-15), mineral bileşik (\%3), karbonhidrat, vitamin ve şeker (\%2.5-4.0) içerdiğinden dolayı sağıklı beslenmede iyi bir diyet meyvesi özelliği taşımaktadır (Mitrovic ve ark., 1997). $100 \mathrm{~g}$ iç cevizde yaklaşık $630.00 \mathrm{kcal}$ enerji, $14.10 \mathrm{~g}$ protein, $68.00 \mathrm{~g}$ toplam yağ, $3.20 \mathrm{~g}$ toplam karbonhidrat, $9.70 \mathrm{~g}$ selüloz, $1.80 \mathrm{~g}$ kül ve $3.20 \mathrm{~g}$ nem bulunmaktadır. Yine mineral maddelerden önemli düzeyde fosfor (348.00 mg), potasyum (391.00 mg),

Sorumlu Yazar: ercanyildiz@erciyes.edu.tr

Geliş Tarihi: 10 Mayıs 2019

Kabul Tarihi: 17 Aralık 2019 
kalsiyum (89.00 mg), magnezyum (113.00 mg), sodyum (10.00 mg) ve demir (2.40 mg) içeriğine sahip olduğu bildirilmiştir (Akça, 2009). Ceviz içerdiği yüksek miktardaki makro ve mikro elementler sayesinde, insan kanındaki iyi kolestrolü arttırıcı kötü kolestrolü ise azaltıcı (Davis ve ark., 2007), ayrıca kalp krizinin (Bloomhoff ve ark., 2006) ve diyetten kaynaklanan hastalıkların önlenmesi ile kardiyovasküler hastalıklardan koruyucu (Banel ve $\mathrm{Hu}$, 2009; Ros, 2009) ve kan basıncını düzenleyici (Elin, 1993) etkilere sahiptir.

Ülkemizin değişik bölgelerinde doğal olarak yetişen ceviz genotiplerinde, meyvelerin mineral madde içeriklerinin tespiti konusunda geçmişten günümüze çeşitli çalışmalar yapılmıştır (Özrenk ve ark., 2005; Muradoğlu ve Balta, 2010; Muradoğlu ve ark., 2011; Çelik ve ark., 2011; Yerlikaya ve ark., 2012; Ertürk ve ark., 2014; Polat ve ark., 2015; Gülsoy ve ark., 2016a; 2016b; Yılmaz ve Akça, 2017). Ancak zengin ceviz genotip potansiyeline sahip Uşak ilinde bu konuda yapıımış çalışma bulunmamaktadır. Bu noktadan hareketle planlanan bu çalışmada, Uşak ilinden seçilen ümitvar ceviz genotiplerinde meyvelerin mineral madde içeriklerinin belirlenmesi hedeflenmiştir.

\section{MATERYAL VE YÖNTEM}

Araştırmanın materyalini Uşak ilinden 2015-2017 yılları arasında gerçekleştirilen seleksiyon çalışmasında ümitvar olarak seçilen ve farklı lokasyonlarda yer alan 21 adet ceviz genotipi oluşturmuştur. Şen (1980) ve Özkan (1996) tarafından önerildiği gibi, 2018 yılında her ağaçtan alınan 20 adet ceviz meyvesinin yeşil kabukları çıkarıldıktan sonra, bu örnekler özel olarak hazırlanan numaralandırılmış bez torbalar içerisinde muhafaza edilerek gölgede oda sıcaklığında kurumaya bırakılmıştır. Örnekler daha sonra homojen bir kuruma sağlamak amacıyla hava üflemeli $43^{\circ} \mathrm{C}^{\prime}$ ye ayarlanmış etüvde 24 saat süreyle tutulmuştur. Sert dış kabuklarından ayrılan örnekler $1 \mathrm{~mm}$ elek çapına sahip değirmende öğütülmüş ve besin elementi analizleri gerçekleştirilmiştir.

Öğütülmüş ceviz örneklerinden tartılan $1 \mathrm{~g}$ örnek içerisindeki azot (N) içerikleri Lees (1971) tarafından önerilen "Kjheltec" yöntemine göre belirlenmiştir. Makro elementlerden potasyum (K), fosfor (P), kalsiyum (Ca) ve magnezyum ( $\mathrm{Mg}$ ) ile mikro elementlerden demir (Fe), çinko $(\mathrm{Zn})$, mangan (Mn) ve bakır (Cu) içeriklerinin tayininde Kacar (1972) tarafından belirtilen kuru yakma yöntemi uygulanmıştır. Bu yönteme göre ceviz örnekleri önce 550 ${ }^{\circ} \mathrm{C}$ 'de yakılmış ve sonra üzerlerine $5 \mathrm{~mL} \% 20$ 'lik $\mathrm{HCL}$ solüsyonu ilave edilmiş ve son hacim saf su ile $50 \mathrm{~mL}^{\prime} y e$ tamamlanmıştır. Makro ve mikro elementler Chapman ve Pratt (1961) tarafından önerilen spektrometrik yöntem temel alınarak Spectro Arcos Model ICP-OES cihazındatespit edilmiştir. Çalışmada, element içeriklerinden azot \% olarak, 180 diğer elementler ise $\mathrm{mg} / 100 \mathrm{~g}$ olarak ifade edilmiştir. Çalışmada kullanılan her bir ceviz genotipi tek bir ağaç olduğundan varyans analizi (ANOVA) yapılmamıştır.

\section{BULGULAR VE TARTIŞMA}

Uşak ilinden ümitvar olarak seçilen 21 adet ceviz genotipinde meyvelere ait makro ve mikro mineral madde içerik sonuçları Çizelge 1'de verilmiştir. Genotiplerin meyvelerinde azot $(\mathrm{N})$ hariç makro element miktarının potasyum $(\mathrm{K})>$ fosfor $(\mathrm{P})>$ kalsiyum $(\mathrm{Ca})>$ magnezyum $(\mathrm{Mg})$ şeklinde sıralandığı tespit edilmiştir. iç ceviz meyvelerinde N miktarı \%2.10 (UŞAK-42) ile \%3.40 (UŞAK13) arasında belirlenirken, genotiplerde ortalama $N$ içeriği \%2.94 olarak saptanmıştır. N içeriği açısından UŞAK-13 nolu genotipden sonra UŞAK-5 (\%3.39) ve UŞAK-36 (\%3.37) nolu genotipler öne çıkmıştır. Çalışmada yer alan genotiplerin meyvelerinde $P$ miktarı (mg/100 g) en yüksek 411.15 ile UŞAK-34, en düşük 210.93 ile UŞAK-2 nolu genotiplerde tespit edilirken, ortalama miktar ise 324.60 olarak belirlenmiştir. Meyve $\mathrm{K}$ içeriği en fazla UŞAK-34 nolu genotipte (480.82 mg/100 g) belirlenirken, bunu UŞAK-18 nolu genotip (471.76 mg/100 g) takip etmiştir. En düşük K içeriği (mg/100 g) UŞAK-2 nolu genotipte 308.61 ile elde edilirken, genotiplerde ortalama içerik 428.93 olarak saptanmıştır. Çalışmada incelenen genotiplerde $\mathrm{Ca}$ miktarına (mg/100 g) ait en yüksek değer 379.61 ile UŞAK27, en düşük değer ise 149.63 ile UŞAK-22 nolu genotiplerde saptanırken, bu iki genotip arasında yaklaşık 2.5 katlık bir fark ortaya çıkmıştır. Genotiplerde ortalama $\mathrm{Ca}$ içeriği ise $199.18 \mathrm{mg} / 100 \mathrm{~g}$ olmuştur. Incelenen genotiplerin meyvelerinde Mg miktarı (mg/100 g) 132.39 (UŞAK-2) ile 224.81 (UŞAK-20) arasında belirlenirken, genotiplerde ortalama Mg içeriği 187.98 olarak saptanmıştır.

Araştırmada yer alan 21 adet ceviz genotipin meyvelerine ait demir (Fe), çinko ( $\mathrm{Zn})$, mangan $(\mathrm{Mn})$ ve bakır (Cu) içeriklerinin (mg/100 g) ortalaması sırasıyla 3.25, 2.26, 3.43 ve 1.51 olarak belirlendiği, meyvelerdeki mikro element miktarının ise $\mathrm{Mn}>\mathrm{Fe}>\mathrm{Zn}>\mathrm{Cu}$ şeklinde sıralandığı tespit edilmiştir.

İç ceviz meyvelerinin Fe içeriği en yüksek UŞAK-36 (3.95 $\mathrm{mg} / 100 \mathrm{~g})$, UŞAK-32 (3.91 mg/100 g) ve UŞAK-18 (3.90 $\mathrm{mg} / 100 \mathrm{~g})$ nolu genotiplerde saptanırken, en düşük değer 2.22 mg/100 g ile UŞAK-49 nolu genotipte tespit edilmiştir. Genotiplerin Zn içerikleri değerlendirildiğinde UŞAK-18 nolu genotip (3.26 mg/100 g) en yüksek, UŞAK-39 nolu genotip $(1.62 \mathrm{mg} / 100 \mathrm{~g})$ ise en düşük değere sahip olmuştur. Meyve $\mathrm{Mn}$ içeriği en fazla UŞAK-18 nolu genotipte $(4.45 \mathrm{mg} / 100 \mathrm{~g})$ belirlenirken, bunu UŞAK-38 nolu genotip (4.41 mg/100 g) takip etmiştir. En düşük $\mathrm{Mn}$ içeriği (mg/100 g) ise UŞAK-42 nolu genotipte 1.70 ile elde edilmiştir. Incelenen genotiplerde meyvelerin $\mathrm{Cu}$ miktarı en yüksek UŞAK-42 
Çizelge 1. Ümitvar seçilen genotiplerde meyvelerin makro ve mikro mineral madde içerikleri

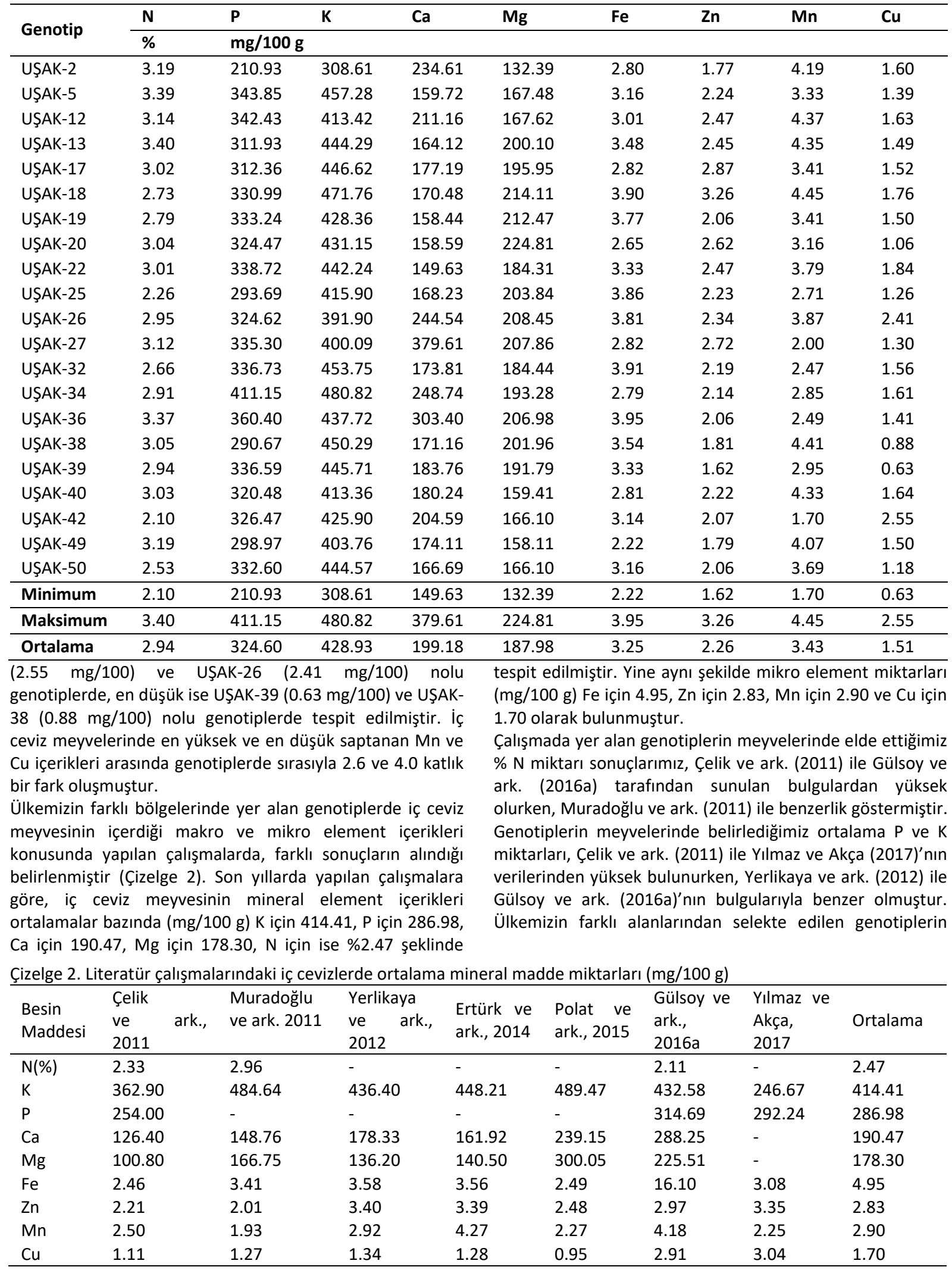


meyvelerinde saptanan $\mathrm{K}$ içeriğinin, bulgularımızdan yüksek olduğu Muradoğlu ve ark. (2011), Ertürk ve ark. (2014) ile Polat ve ark. (2015) tarafından bildirilmiştir. Çalışmada incelenen genotiplerde meyvelerin $\mathrm{Ca}$ ve $\mathrm{Mg}$ içerikleri Çelik ve ark. (2011), Muradoğlu ve ark. (2011), Yerlikaya ve ark. (2012) ile Ertürk ve ark. (2014)'nın sonuçlarından yüksek, Polat ve ark. (2015) ile Gülsoy ve ark. (2016a)'nın sonuçlarından ise düşük olarak saptanmıştır. Genotiplerin meyvelerinde elde ettiğimiz mikro mineral madde içerikleri literatürle karşılaştırdığımızda oldukça farklı durum ortaya çıkmaktadır. Örneğin meyvelerin Fe, Zn, Mn ve $\mathrm{Cu}$ içerikleri ile ilgili bulgularımız, Tavas (Denizli) bölgesinden selekte edilen 9 genotipden (Çelik ve ark., 2011) daha yüksek, Iğdır ilinden selekte edilen 16 genotipden (Gülsoy ve ark., 2016a) ise daha düşük bulunmuştur. Ertürk ve ark. (2014) tarafından Şebinkarahisar (Giresun) bölgesinden selekte edilen 7 genotip ile yerli çeşitlerden Şebin çeşidinin meyvelerinde saptanan ortalama $\mathrm{Fe}, \mathrm{Zn}$ ve $\mathrm{Mn}$ içeriklerinin bulgularımızdan yüksek, $\mathrm{Cu}$ içeriklerinin ise düşük olduğu bildirilmiştir. Yine mikro element içerikleri ile ilgili elde ettiğimiz bulgular, Muradoğlu ve ark. (2011) tarafından Bingöl yöresinden seçilen 17 genotipde saptanan veriler (Fe içeriği hariç) ile Polat ve ark. (2015) tarafından Bitlis yöresinden seçilen 17 genotipde belirlenen verilerden ( $\mathrm{Zn}$ içeriği hariç) daha yüksek bulunmuştur. Yılmaz ve Akça (2017) tarafından Niksar (Tokat) yöresinden seçilen 14 genotipin meyvelerinde belirlenen $\mathrm{Fe}$ ve $\mathrm{Mn}$ içeriği, bulgularımızdan düşük, $\mathrm{Zn}$ ve $\mathrm{Cu}$ içeriği ise yüksek bulunmuştur.

Araştırma sonucunda elde edilen bulgular gerek ülkemizde önemli ticari çeşit olan Şebin çeşidi gerekse USDA'nın (Anonim, 2018b) iç ceviz meyvesindeki besin elementi içerik değerleri ile kıyaslanmıştır (Çizelge 3).

Çizelge 3. Literatür çalışmalarında Şebin çeşidine ait iç ceviz mineral madde miktarları (mg/100 g)

\begin{tabular}{lllllllll}
\hline Araştırıcılar & $\mathrm{P}$ & $\mathrm{K}$ & $\mathrm{Ca}$ & $\mathrm{Mg}$ & $\mathrm{Fe}$ & $\mathrm{Zn}$ & $\mathrm{Mn}$ & $\mathrm{Cu}$ \\
\hline Çağlarırmak, 2003 & 280.00 & 240.00 & 74.00 & 81.00 & 2.46 & 1.80 & 1.87 & 0.94 \\
\hline Akça ve ark., 2005 & - & 347.00 & 319.00 & 146.00 & 1.90 & 1.90 & 2.30 & 0.90 \\
\hline Yerlikaya ve ark., 2012 & - & 359.73 & 200.39 & 156.33 & 3.68 & 2.94 & 4.32 & 1.55 \\
\hline USDA* değeri & 346.00 & 441.00 & 98.00 & 158.00 & 2.91 & 3.09 & 3.41 & 1.58 \\
\hline
\end{tabular}

\section{*(Anonim 2018b)}

\section{KAYNAKLAR}

Akça Y, Sütyemez M, Özgen M, Tüzen M, Mendil D (2005) Determination of Chemical Properties of Walnut (Juglans regia L.) Cultivars Grow in Turkey. Asian Journal of Chemistry 1: 548-552.

Akça Y (2009) Ceviz Yetiştiriciliği. Anı Matbaası, Ankara.

Anonim (2017) FAO (Food and Agriculture Organization of the United Nations). http://fao.org/page/collections?subset=agriculture. Erişim Tarihi: 12/03/2019.

Anonim (2018a) TUiK (Türkiye İstatistik Kurumu, "Bitkisel Üretim İstatistikleri") http://www.tuik.gov.tr/medas/?kn=92\&locale=tr. Erişim Tarihi: 12/03/2019.

Anonim (2018b) USDA (National Nutrient Database for Standard Reference). http://ndb.usda.gov/ndb/. Erişim Tarihi: 25/02/2019.
Çalışmada yer alan genotiplerin meyvelerinde elde ettiğimiz mineral madde içerikleri, Çağlarırmak (2003) ile Akça ve ark. (2005) tarafından ülkemizde farklı bölgelerde yetiştirilen Şebin çeşidinde belirlenen bulgulardan yüksek bulunmuştur. Buna karşın, Yerlikaya ve ark. (2012) Şebin çeşidinin $\mathrm{Fe}, \mathrm{Zn}$ ve $\mathrm{Mn}$ içeriklerinin bulgularımızdan daha yüksek, $\mathrm{Ca}$ ve $\mathrm{Cu}$ içeriklerinin benzer, $\mathrm{P}$ ve $\mathrm{Mg}$ içeriklerinin ise daha düşük olduğunu bildirmiştir. Çalışmamızda genotiplerin meyvelerinde elde ettiğimiz ortalama $\mathrm{Mn}$ ve $\mathrm{Cu}$ içerikleri USDA değerleriyle benzerlik gösterirken, $\mathrm{K}, \mathrm{P}$ ve $\mathrm{Zn}$ içeriklerimizin daha düşük, $\mathrm{Ca}, \mathrm{Mg}$ ve Fe içeriklerimizin ise daha yüksek olduğu saptanmıştır.

\section{SONUÇ}

Çalışmada yer alan genotiplerin bazılarının yerli çeşidimiz Şebin ile kıyaslandığında mikro ve makro mineral madde içerikleri bakımından üstün oldukları tespit edilmiştir. Genotiplerin mineral madde içerikleri topluca ele alındığında gerek miktar gerekse çeşitlilik açısından farklı mineral madde içeriklerini bünyesinde bulundurduğu saptanmıştır. Bu durum ülkemizde gerek genotipler gerekse çeşitler bazında yapılan çalışmalarda da ortaya çıkmıştır. Literatüre konu olan bu değişik sonuçlar, genotiplerin genetik yapıları, bulunduğu alanların toprak ve iklim özellikleri, bahçelerde uygulanan yıllık bakım işlemleri, hasat zamanı ve uygulanan metodolojinin farklılığından kaynaklanabilir. Özellikle çalışmalarda yer alan genotiplerin modern bahçelerde yetiştirilmesi halinde mineral madde içeriklerinin artması kaçınılmazdır. Yeni çeşit eldesine yönelik uygulanan ıslah programlarında, çeşit adayları sağlık açısından da değerlendirilmektedir. Bu açıdan önem arz eden genotiplerin çoğaltılıp koruma altına alınması ülkemiz genetik kaynakların korunmasını açısından önemli olacaktır.
Banel DK, Hu FB (2009) Effects of Walnut Consumption on Blood Lipid Sand other Cardiovascular Risk Factors: A Meta-Analysis and Systematic Review. American Journal of Clinical Nutrition 90: 56-63.

Bloomhoff R, Carlsen M, Andersen LF, Jacobs DR (2006) Health Benefits of Nuts: Potential Role of Antioxidants. British Journal of Nutrition 96: 52-60.

Chapman HD, Pratt PF (1961) Method of Analysis for Soils, Plant Sand Waters. University of California, Division of Agricultural Sciences, California.

Çağlarırmak N (2003) Biochemical and Physical Properties of Some Walnut Genotypes (Juglans regia L.). Nahrung/Food 47: 28-32.

Çelik F, Cimrin KM, Kazankaya A (2011) Tavas (Denizli) Yöresinden Selekte Edilen Ceviz (Juglans regia L.) Genotiplerinin Bazı Fiziksel ve Kimyasal Özellikleri. Yüzüncü Yıl Üniversitesi Tarım Bilimi Dergisi 21: 42-48. 
Davis L, Stonehouse W, Loots DT, Mukuddem-Petersen J, van der Westhuizen F, Hanekom SJ, Jerling JC (2007) The Effects of High Walnut and Cashew Nut Diets on the Antioxidant Status of Subjects with Metabolic Syndrome. European Journal of Nutrition 46: 155-164.

Elin RJ (1993) Is the Magnesium Content of Nuts a Factor for Coronary Heart Disease? Archives of Internal Medicine 153: 779-780.

Ertürk U, Şişman T, Yerlikaya C, Ertürk O, Karadeniz T (2014) Chemical Composition and Nutritive Value of Selected Walnuts (Juglans regia L.) from Turkey. Acta Horticulturae 1050: 231-234.

Gülsoy E, Kaya T, Pehluvan M, Şimşek M (2016a) Iğdır İlinden Seçilen Ceviz (Juglans regia L.) Genotiplerinin Bazı Pomolojik ve Kimyasal Özellikleri. Anadolu Tarım Bilimleri Dergisi 31: 309-314.

Gülsoy E, Kaya T, Türkan A (2016b) Tuzluca (Iğdır) Bölgesi Ceviz Genotiplerinin Fiziko-Kimyasal Karakterizasyonu. Gaziosmanpaşa Üniversitesi Ziraat Fakültesi Dergisi 33: 166-173.

Kacar B (1972) Bitki ve Toprağın Kimyasal Analizleri. Ankara Üniversitesi Ziraat Fakültesi Yayınları, Ankara.

Less R (1971) Laboratory Handbook of Methods of Food Analysis. Leonard Hill Boks, London.

Mitroviç M, Stanisavljevic M, Danjanov JG (1997) Biochemical Composition of Fruits of Some Important Walnut Cultivar Sand Selections. Acta Horticulturae 442: 205-207.

Muradoğlu F, Balta F (2010) Ahlat (Bitlis) Yöresinden Selekte Edilen Cevizlerin (Juglans regia L.) Bazı Fiziksel ve Kimyasal Özellikleri. Yüzüncü Yıl Üniversitesi Tarım Bilimleri Dergisi 20: 41-45.

Muradoğlu F, Gündoğdu M, Kalan C (2011) Bingöl Yöresi Ceviz Genotiplerinin Bazı Kimyasal ve Mineral İçeriklerinin Belirlenmesi. Yüzüncü Yıl Üniversitesi Fen Bilimleri Enstitüsü Dergisi 16: 17-21.
Özkan Y (1996) Niksar ve Pazar İlçelerinde Yetişen Bazı Ceviz Tiplerinin Meyve Özellikleri. Gaziosmanpaşa Üniversitesi Ziraat Fakültesi Dergisi 13: 1-13.

Özrenk K, Güleryüz M, Kazankaya A, Balta MF, Yarılgaç T (2005) Erzincan Yöresinden Selekte Edilmiş Ceviz (Juglans regia L.) Seleksiyonlarının Bazı Kimyasal Özelliklerinin Belirlenmesi. Bahçe (Ceviz) 34: 171-175.

Polat M, Okatan V, Güçlü SF (2015) Determination of Some Physical and Chemical Properties of Walnut (Juglans regia L.) Genotypes Grown in the Central District of Bitlis/Turkey. Scientific Papers Series B Horticulture LIX: 81-86.

Ros E (2009) Nuts and Novel Biomarkers of Cardiovascular Disease. American Journal of Clinical Nutrition 89: 1649-1656.

Şen SM (1980) Kuzey Doğu Anadolu ve Doğu Karadeniz Bölgesi Cevizlerinin (Juglans regia L.) Seleksiyon Yolu ile Islahı Üzerinde Araştırmalar. Doçentlik Tezi, Atatürk Üniversitesi, Erzurum.

Şen SM (1986) Ceviz Yetiştiriciliği. Eser Matbaası, Samsun.

Tapia MI, Sanchez-Margado JR, Garcia-Parra J, Ramirez R, Hernandez T, Gonzales-Games D (2013) Comparative Study of the Nutritional and Bioactive Compounds Content of Four Walnut (Juglans regia L.) Cultivars. Journal of Food Composition and Analysis 31: 232237.

Yerlikaya C, Yücel S, Ertürk Ü, Korukluoğlu M (2012) Composition of Juglans regia L. Genotypes and Cultivars Grown in Turkey. Brazilian Archives of Biology and Technology 55: 677-683.

Yılmaz S, Akça Y (2017) Determination of Biochemical Properties and Fatty Acid Composition of New Walnut (Juglans regia L.) Genotypes. Gaziosmanpașa Üniversitesi Ziraat Fakültesi Dergisi 34: 74-80. 
